\title{
Estado actual en el tratamiento de la enfermedad de Chagas
}

\author{
WERNER APT B., INÉS ZULANTAY A. ${ }^{\mathrm{a}}$
}

\section{Update on the treatment of Chagas' disease}

Efficient drugs against Chagas' disease must have an effect on the amastigote forms or intracellular reproduction elements of Trypanosoma cruzi (T. cruzi). Trypomastigote and epimastigote forms derive from the former and their response to medications is less marked. The only drugs used in humans are nifurtimox (NF) and benznidazole (BNZ). Other useful medications are allopurinol and itraconazole. NF acts producing free radicals and BNZ inhibits the synthesis of macromolecules. There is consensus that Chagas' disease must be treated in all its periods, since T.cruzi DNA is detected by polymerase chain reaction in chronic cases, even when microscopy is negative. The pharmacological treatment modifies the natural evolution of the disease. It also helps to solve a public health problem, considering that there is a high number of subjects with Chagas' disease. Subjects with chronic chagasic cardiomyopathy with terminal heart failure are the only cases without indication for treatment. Due to the digestive and skin secondary effects of the drugs, treated patients must be controlled clinically and with complete blood counts and hepatic profiles before, during and after the therapy. Approximately 30\% of patients will experience secondary effects. Children have a better tolerance to the drugs. Congenital or acquired acute, intermediate and chronic cases should be treated.

(Rev Med Chile 2011; 139: 247-257).

Key words: Benzonidazole; Chagas cardiomyopathy; Chagas disease.

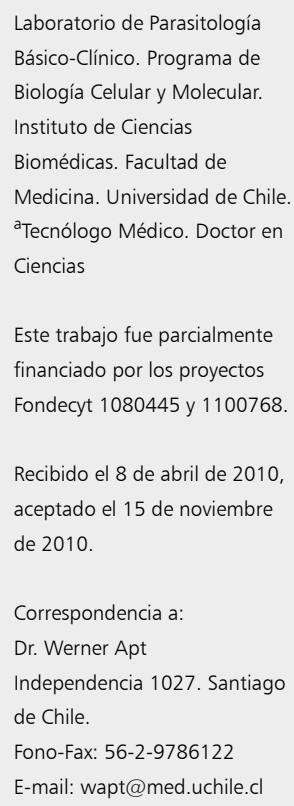

L a enfermedad de Chagas (ECh) existe en el continente americano desde hace más de 9.000 años. En restos de momias humanas exhumadas de regiones costeras y valles del norte de Chile y sur de Perú, se demostró la presencia de Trypanosoma cruzi (T. cruzi) mediante la técnica de PCR y sondas de hibridación de kDNA. Estas momias corresponden a grupos culturales que vivieron desde los 7.000 años AC hasta 1.500 DC, es decir, hasta la conquista de los españoles, y corresponden a los primeros humanos en América (cultura Chinchorro) ${ }^{1}$. Si bien la ECh es una parasitosis antigua, su tratamiento es de reciente aplicación ${ }^{2}$. La terapia humana actual con nifurtimox (NF) y benznidazol (BNZ) se inicia en la década $1970-1980^{3-5}$. Para que un fármaco sea eficaz en la ECh, debe actuar sobre las formas amastigotas de T. cruzi, es decir, los elementos de reproducción celular en los animales mamíferos, ya que las formas epimastigotas y tripomastigotas derivan de las primeras y por consiguiente su respuesta a medicamentos tiene menos importancia ${ }^{6-8}$. Hace 25 años efectuamos una puesta al día sobre la terapia etiológica de la $\mathrm{ECh}^{2} \mathrm{y}$ desde entonces se han producido avances en el tratamiento de esta zoonosis. En la Tabla 1 se describen los fármacos más importantes que actúan sobre las formas amastigotas de T. cruzi y su mecanismo de acción ${ }^{8}$. Es importante mencionar que si bien existen reservorios animales de la ECh, hasta la fecha no se ha demostrado la enfermedad en animales en su ambiente natural. 
Tabla 1. Fármacos que actúan sobre las formas amastigotas de Trypanosoma cruzi y su principal mecanismo de acción

\begin{tabular}{|c|c|}
\hline Fármaco & Mecanismo de acción \\
\hline Alopurinol & Inhibidor de la síntesis de proteínas y purinas \\
\hline Itraconazol y Posaconazol & Inhibición de la síntesis de ergoesterol \\
\hline Butionina-Sulfaximina (BSO) & Inhibe el metabolismo del tripanotión \\
\hline Cruzipaina, Miltafosina & $\begin{array}{l}\text { Inhibe las proteasas de cisteina (CPI) } \\
\text { Inhibe la biosíntesis de fosfatil colina (PC) } \\
\text { Inhibición de las metil carboxipeptidas }\left(^{*}\right)\end{array}$ \\
\hline Alcaloides del boldo y plantas con isoquinolinas & Inhiben la cadena respiratoria \\
\hline Nifurtimox & $\begin{array}{l}\text { Producción de radicales libres: aniones super óxido, peróxido de hidró- } \\
\text { geno y metabolitos electrofilicos }\end{array}$ \\
\hline Benznidazol & Inhibe la síntesis de proteínas y la cadena respiratoria \\
\hline
\end{tabular}

(*) Hasta la fecha no se han realizado estudios con fármacos que inhiban las metilcarboxipeptidasas de T. cruzi, enzimas que no existen en la especie humana y por consiguiente constituyen un blanco ideal.

Fármacos que inhiben la síntesis de proteínas o de purinas

\section{Alopurinol (ALO)}

El T. cruzi no es capaz de sintetizar purinas "de novo" como lo realiza el hombre. El ALO (4-hidroxipirazol $(3,4 \mathrm{~d}$ ) pirimida (HPP) (Figura 1) es un análogo de la hipoxantina que disminuye la producción de ácido úrico al inhibir la conversión de hipoxantinas en xantina. Por este motivo se utiliza en la gota, que se caracteriza por depósito de ácido úrico en las articulaciones. HPP inhibe a las formas epimastigotas de cultivo. En ratones infectados con T. cruzi y tratados con ALO se obtiene una reducción importante de la parasitemia, existiendo algunas cepas de parásitos resistentes al fármaco 9 . T. cruzi convierte HPP en APP (4 aminopirazol (3,4d) (pirimidina) que es 15 veces más potente contra formas epimastigotas que HPP. Si se administra APP a ratones infectados con T. cruzi se obtiene supresión de la parasitemia con dosis 400 veces inferiores que las del $\mathrm{ALO}^{10}$. En pacientes agudos tratados con altas dosis (20$30 \mathrm{mg}$ al día) por 60 días, no se obtuvo reducción de la carga parasitaria. Un estudio multicéntrico realizado en Argentina, Brasil y Bolivia en pacientes con ECh crónica con dosis de $900 \mathrm{mg}$ al día por 60 días, no se logró curación parasitológica. Este fármaco ha sido bien tolerado en diversos estudios realizados en pacientes con ECh crónica $y$ en algunos de ellos ha demostrado mejorar las alteraciones electrocardiográficas de los pacientes con cardiopatía chagásica crónica (CCC $)^{11}$. Se le ha utilizado en pacientes trasplantados cardiacos con buen rendimiento ${ }^{12}$. En casos excepcionales ha sido necesario suspender el tratamiento por los efectos secundarios que origina ${ }^{13}$.

MK-436.2 3(metil-5 nitroimidazol-2 il)

$3 \alpha$ hexahidro-1,2- benzisoxazol

Es un sustituto del 5-nitroinidazol y su derivado dehidro (L-634, 549). Tiene efecto sobre formas amastigotas de cultivos de tejidos y en infecciones agudas y crónicas de ratones. Con este fármaco se obtiene curación parasitológica de los animales infectados. Hasta la fecha no se ha utilizado MK436 en pacientes con ECh.

\section{Inhibidores del ergoesterol}

Diversos compuestos azólicos se han utilizado con éxito en medicina humana y veterinaria. Estos fármacos interfieren en la síntesis de los esteroles y junto con otros compuestos nitrogenados heterocíclicos, pertenecen al grupo de fármacos que inhiben la síntesis del ergoesterol. T. cruzi tiene ergosterol y los antimicóticos impiden su síntesis sin afectar al hospedero humano que tiene colesterol. El colesterol difiere del ergosterol por la presencia de un grupo metilo 24 y dobles enlaces en A7 y A22. Las tres enzimas que permiten 


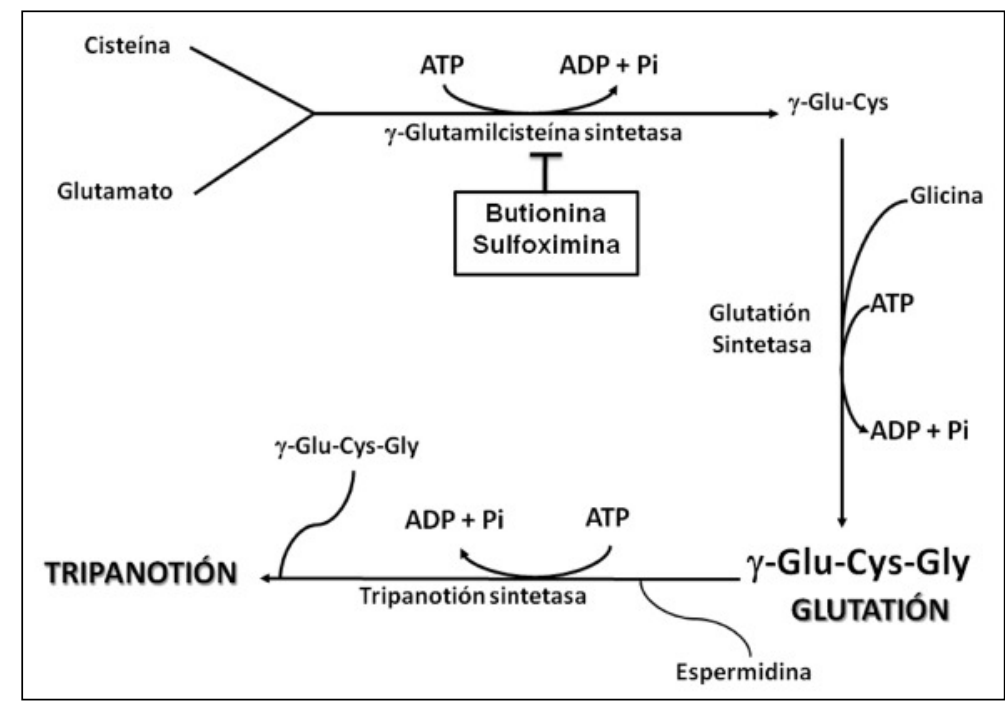

Figura 1. Biosíntesis del glutatión y tripanotión en Trypanosoma cruzi: Glutatión es sintetizado por la acción consecutiva de las sintetasas de $\gamma$-glutamilcisteina y de glutatión en una reacción dependiente de ATP. En T. cruzi, dos moléculas de glutatión se conjugan con spermidina para sintetizar tripanotión (N1,N8-bisglutationil spermidina, $\mathrm{T}(\mathrm{SH})_{2}$ ). El hospedero es incapaz de sintetizar $\left.\mathrm{T}(\mathrm{SH})_{2}\right)$. La sintetasa de $\gamma$-glutamilcisteina es el paso enzimático limitante en este proceso y puede ser inhibido por butionina sulfoximina (BSO). la mutilación y los dobles enlaces del ergoesterol no tienen contrapartida en los mamíferos en relación a la síntesis de colesterol. Varios de estos productos azólicos se han estudiado en la ECh: miconazol econazol, ketoconazol (KETO), itraconazol (ITRA), fluconazol y posaconazol
(POSA). Con estos fármacos se ha obtenido cura parasitológica en ratones con infección aguda y crónica ${ }^{14}$. KETO, ITRA y el compuesto DO 870 inhiben la citocromo P450 dependiente de la lenosterol-14 demetilasa, disminuyendo por este mecanismo la síntesis de ergoesterol. Si bien los

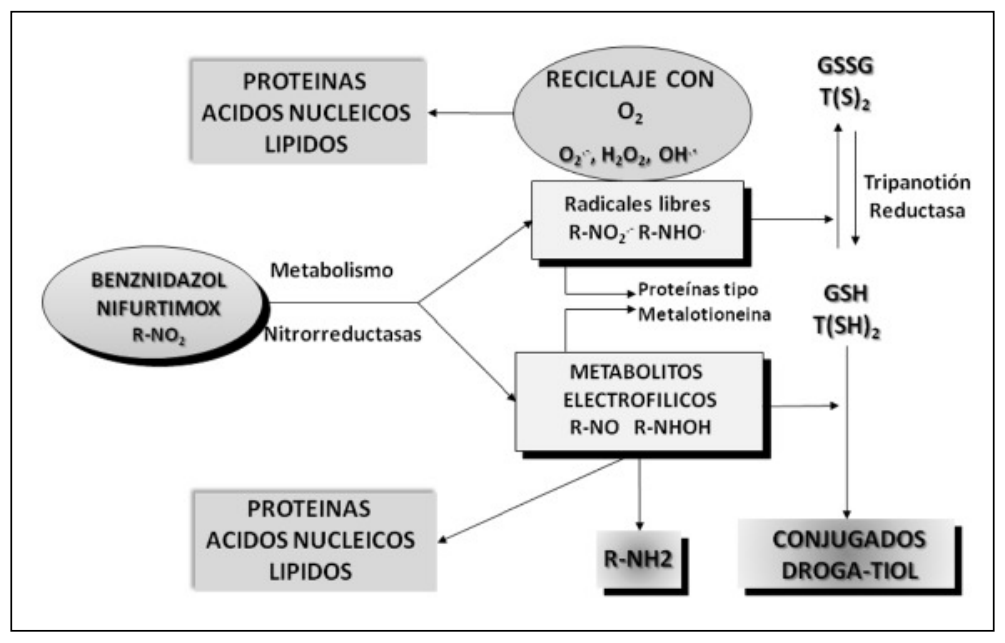

Figura 2. Rol del glutatión y tripanotión en el metabolismo de los fármacos antichagásicos nifurtimox y benznidazol. El grupo nitro de ambos fármacos antichagásicos es reducido a radicales libres o metabolitos electrofilicos por la citocromo P450 y microreductasas relacionadas de T. cruzi. Los radicales libres derivados del nifurtimox pueden seguir un proceso de oxidoreducción cíclico en presencia de oxígeno originando $\mathrm{H}_{2} \mathrm{O}_{2}$ por la acción previa de la dismutasa superóxido (SOD). El oxígeno producido, los radicales libres y metabolitos electrofilicos se unen a macromoleculas intracelulares dañándolas. En el parásito, tripanotion $\left(\mathrm{T}(\mathrm{SH})_{2}\right.$ ) y glutation (GSH) neutralizan los metabolitos derivados del nifurtimox y benznidazol mediante conjugación originando conjugados fármacos-tiol que posteriormente son metabolizados hacia mercapturatos en el hospedero mamífero. Los radicales libres son neutralizados por oxidación de GSH o T(SH) 2 reducidos. La tripanotion reductasa reduce a la tripanotion oxidada $\left(\mathrm{T}(\mathrm{S})_{2}\right)$. 
mamíferos poseen esa enzima, es mucho menos sensible a los fármacos que la de los hongos o la de T. cruzi. ITRA se ha utilizado en el tratamiento de pacientes con ECh crónica indeterminada y con CCC. El fármaco previene la cardiopatía en relación a controles sin terapia y mejora el 50\% de las alteraciones electrocardiográficas de los pacientes con CCC. En 20\% de estos casos "cura parasitológicamente", determinado mediante exámenes seriados de xenodiagnóstico, PCR y sondas de hibridación en sangre, PCR en deyecciones y sondas de hibridación de deyecciones de triatominos aplicados a estos pacientes. Ninguna de las personas "curadas" presenta serología convencional (HAI, IFI o ELISA) negativa para $T$. cruzi $^{11,15}$. Se ha demostrado que al administrar el fármaco DO 870 a ratones con infección aguda $\left(10^{5}\right.$ T. cruzi cepa $\left.\mathrm{Y}\right)$, los animales tratados vivieron más que los controles sin terapia o tratados con NF o KETO, 105 días de sobrevida versus 21 . Se obtuvo $60 \%$ de curación mediante controles de parasitemia, hemocultivos y PCR. Al aplicar esta terapia en ratones con infección crónica $\left(10^{4} \mathrm{~T}\right.$. cruzi cepa Bertoldo), a los 40-50 días la curación parasitológica fue de 50\% (80-90\% de curación), pero $50 \%$ de los controles sobrevive con $30 \%$ de PCR negativos ${ }^{14}$. Hoy en día DO 870 ha sido descontinuado, pero POSA (SCH 56592), BMS207, 147 (ravuconazol), VR-9825 y TAK-187, han demostrado tener actividad anti T. cruzi " in vitro" e "in vivo". De estos compuestos POSA ha demostrado ser eficaz y con muy buena tolerancia en estudios realizados en pacientes con candidiasis orofaríngea $^{16}$. Recientemente se ha observado que la mayoría de estos compuestos (POSA, ravuconazol, VR-9825 y TAK-187) tienen acción sobre cepas de T. cruzi parcialmente resistentes a NF, BNZ y donde KETO no tiene rendimiento ${ }^{17}$. Tanto posaconazol como ravuconazol son los fármacos que tienen mayores expectativas en la terapia humana en un futuro próximo.

\section{Inhibidores del metabolismo del tripanotión}

Tripanotion ( $\mathrm{N}^{1}, \mathrm{~N}^{8}$-bis) (glutatyonil)-spermidina (Figura 1) y la tripanotion reductasa son sistemas únicos en los protozoos kinetoplastidos que reemplazan el glutatión y la glutatión reductasa intracelular, mecanismo principal del sistema tiol-redox. Si bien la tripanotion reductasa es una enzima esencial en Leishmania donovani y $L$. mayor, la sobre expresión de la enzima en $L$. donovani y T. cruzi no altera su sensibilidad "in vitro" a agentes que inducen estrés oxidativo como NF, nitrofurazona y violeta de genciana. Inhibidores del metabolismo del tripanotion como butionine sulfaximine (BSO) son candidatos potenciales ideales como fármacos anti T. cruzi, solos o juntos a drogas productoras de radicales libres como NF y BNZ ${ }^{18}$ (Figura 2).

\section{Inhibidores de las proteasas cisteína}

La cruzipaina (cruzaina, gp 51/57) es una catepsina L-cisteina proteasa similar responsable de las actividades proteolíticas de todos los estados evolutivos de T. cruzi. Los genes que codifican esta proteína se han clonado y expresado. Se ha elaborado una enzima recombinante y se han estudiado una serie de fármacos inhibidores de CPI que inhiben específicamente esta proteasa "in vitro" bloqueando la proliferación de formas epimastigotas, amastigotas y deteniendo la metaciclogénesis. Se ha demostrado que estos fármacos bloquean el desarrollo de la cruzipaína y su transporte por lisosomas. Estos hechos indican que la cruzipaina es un blanco ideal, pero hasta la fecha si bien CPI se ha utilizado en modelos murinos con infección aguda y crónica, obteniendo curación parasitológica con una toxicidad mínina, la corta vida media del fármaco, requirió grandes dosis y un aumento continuo de ellas para obtener efecto. Hasta la fecha no se ha aplicado en humanos ${ }^{19}$.

\section{Inhibidores de fosfolípidos}

Los alcalil-lisofosfolípidos (ALP) son derivados sintéticos análogos de los lisofosfolípidos que han demostrado ser efectivos "in vitro" e "in vivo" sobre T. cruzi y sobre tripanosomátidos. Miltefosina, uno de sus representantes, se está utilizando por vía oral en la leishmaniasis visceral con buenos resultados. ALP bloquea en forma selectiva la biosíntesis de fofatidil colina (PC) de T. cruzi a través de la vía de trans metilación de Greenberg en contraste con el hospedero vertebrado donde la vía del CDP-colina de Kennedy es la elección ${ }^{17}$. 


\section{Inhibidores del metabolismo de los pirofosfatos}

Los pirofosfatos inorgánicos $\left(\mathrm{P}_{2} \mathrm{O}_{7}^{4}\right.$ y $\left.\mathrm{PPi}\right)$ y otros de cadenas cortas, tri y tetra polifosfatos son los que tienen mayor energía de compuestos fosfatos en los tripanosomatidos (T. cruzi, T. brucei y L. mexicana) y parásitos Apicomplexa (Toxoplasma gondii). Tiene $10-15$ veces mayor energía que ATP. $\mathrm{PPi}$, se distribuye en toda la célula pero se concentra en los ácidocalcisomas, que son vacuolas ácidas con grandes cantidades de $\mathrm{Ca}^{++}$. Enzimas PPi de $T$. cruzi como la proton-translocación pirofosfatasa en ácidocalcisomas y la piruvato fosfato diquinasa en glicosomas confirma que PPi cumple un rol en la supervivencia del parásito. Esto se confirma por las observaciones de que pamidronate, alendronate y risedronate, compuestos nitrogenados bifosfonatos fármacos pirofosfatos análogos (no metabolizados) utilizados habitualmente en medicina humana en trastornos de la reabsorción de huesos, inhiben selectivamente la proliferación de amastigotes intracelulares y taquizoítos de T. gondii. Se ha demostrado que residronate (RIS) actúa "in vitro" sobre formas epimastigotas y amastigotas de cultivos celulares de T. cruzi y mejora la infección de ratones con infección aguda, eliminando casi completamente las parasitemias y las formas amastigotas intracelulares. Este fármaco inhibe la farnesil pirofosfato sintetasa del parásito, bloqueando la biosíntesis de poli-isoprenoides ${ }^{20}$. Hasta la fecha no se ha utilizado este fármaco en el hombre ${ }^{21}$.

Un inhibidor de la farnesiltransferasa el tipifarnib (R 115777) que inhibe la citocromo P450 esterol demetilasa $\left(\mathrm{CYP}_{51}\right)$ constituye un blanco potencial contra T. cruzi, que si bien ha tenido éxito en animales de experimentación, aún no se ha aplicado en humanos.

Se ha estudiado la esterol 14 demerilasa de $T$. cruzi $\left(\mathrm{TCCYP}_{51}\right)$ que está catalíticamente relacionada a la $\mathrm{CYP}_{51}$ de hongos de animales ${ }^{22}$. La inhibición por obtusifolios y sus análogos reduce enormemente la actividad de la enzima. Si bien TCCYP $_{51}$ constituyen un blanco potencial contra T. cruzi, hasta la fecha no se han realizado estudios experimentales para determinar la efectividad de los fármacos en animales.

\section{Inhibidores de las metilcarboxipeptidasas}

Recientemente se ha demostrado que MCPs, metilcarboxipeptidasas pertenecientes a la familia
M32 de las peptidasas está en el citosol de T. cruzi. Hasta la fecha se pensaba que esta enzima existía sólo en bacterias y procariontes. T. cruzi tiene dos MCPs: TcMCP-1 y TcMCP-2. La primera se encuentra en todos los estadios evolutivos del parásito en cambio TcMCP2 sólo existe en formas epimastigotas y tripomastigotas. Por ser una enzima que no existe en humanos, su inhibición podría constituir una terapia efectiva contra T. cruzi $i^{23,24}$.

\section{Fármacos naturales}

Un gran espectro de productos naturales se ha utilizado contra T. cruzi, pero muy pocos son útiles a una concentración de IC50 de $10 \mathrm{ug} / \mathrm{ml}$, considerando que $\mathrm{IC}_{50}$ para NF y BNZ es menor a $3 \mathrm{ug} / \mathrm{ml}$. Algunos productos bloquean la cadena respiratoria del parásito como los alcaloides del boldo y naftoquinonas extraídas de Calceolara sessilis $^{25}$. Otros alcaloides extraídos de plantas brasileras que contienen esoquinolina tienen efecto sobre el T. $\mathrm{cruzi}^{26}$. Algunos fármacos naturales inhiben la respuesta del T. cruzi al estrés oxidativo originando radicales superóxido ${ }^{18}$. Los triterpenos de Arrabidae triplenervia y sus derivados, así como diterpenos, la komariviquinone y terpenoides aislados de Pinus oocarpa, tienen acción sobre formas epimastigotas y tripomastigotas de T. cruzi ${ }^{27-29}$. En la inmensa mayoría no se conoce el mecanismo de acción de estos productos. Gran parte de ellos tienen efecto sobre las formas epimastigotas y algunas sobre amastigotas de cultivos. Muy pocos tienen estudios experimentales en murinos. Ninguno se ha utilizado en estudios clínicos. Hasta la fecha ningún producto natural que tenga efecto sobre la transialidasa de T. cruzi se ha estudiado, no obstante ser esa enzima un blanco óptimo. Un solo fármaco natural se ha utilizado sobre la cistein proteasa (CPI), inhibiendo la síntesis de cruzipaina, este producto es una proteína de 164 aminoácidos reducidos extraída de semillas de Bahuinia balviniodes. No se han efectuado investigaciones experimentales con este fármaco ${ }^{30}$.

\section{Tratamiento de la infección humana}

La terapia de las personas infectadas que utiliza NF y el BNZ data de la década de 19701980 y se basa en un tratamiento empírico ${ }^{31-33}$. El NF (4-([5-Nitrofurfurylidene] amino)-3- 
methylthiomorpholine-1,1-dioxide, Lampit, Bayer), actúa por la producción de radicales libres: aniones superóxido, peróxido de hidrógeno y metabolitos electrofílicos. Se ha demostrado que fuera de la acción metabólica del fármaco sobre $T$. cruzi, es muy importante la incorporación y traspaso de éste por el parásito. Es así como cepas que tienen cierta resistencia al fármaco difieren por la menor captación y transporte de este, más que por la producción de radicales libres. T. cruzi en presencia de NF aumenta su consumo de oxígeno, la producción de $\mathrm{H}_{2} \mathrm{O}_{2}$ y del radical superóxido.

El BNZ (2-Nitro-N-(phenylmethyl)-1Himidazole-1-acetamide) (Figura 6) se introdujo en clínica humana en 1978. El fármaco inhibe la síntesis proteica originando una degradación de la biosíntesis de macromoléculas ${ }^{18}$.

\section{Tratamiento de la enfermedad de Chagas}

Los únicos fármacos que por razones éticas y de eficacia se utilizan en la ECh humana son NF (Lampit ${ }^{\circledR}$ Bayer) y BNZ (Ragonil, Rochagan ${ }^{\circledR}$ Roche). Ambos producen efectos colaterales especialmente en adultos, ya que recién nacidos y niños menores toleran mucho mejor los fármacos ${ }^{34}$. Los efectos secundarios del NF y BNZ se describen en la Tabla 2.

A continuación nos referiremos al tratamiento etiológico de la ECh en los diferentes períodos con los fármacos actualmente en uso.

\section{Indicaciones del tratamiento}

La ECh debe ser tratada siempre, en su período agudo, período crónico determinado inicial e intermedio y en el período crónico indeterminado. Sólo se exceptúan del tratamiento los cardiópatas chagásicos con Core Bovis o insuficiencia cardiaca terminal. Existe consenso en aplicar terapia específica por la demostración de parásitos mediante la reacción en cadena de la polimerasa (PCR) de $T$. cruzi en casos crónicos donde la microscopia óptica no los pesquisa. El tratamiento en estos casos tiene rendimiento ${ }^{6,7}$. En la actualidad se acepta que la terapia precoz es capaz de modificar la evolución natural de la enfermedad. Debido a la cantidad de pacientes con enfermedad de Chagas, alrededor de 12 millones en el continente americano y 150.000 en Chile, su tratamiento es una solución a un problema de Salud Pública ${ }^{35}$.

\section{Casos agudos}

\section{i. Adquiridos}

Deben ser tratados siempre, tanto los pacientes con manifestaciones clínicas, signo de Romaña, chagomas de inoculación, signos de carditis: ritmo de galope, tonos apagados, taquicardia o alteraciones del ECG (alteración ST y T y alteraciones de la conducción auriculo ventricular, etc) como los casos agudos biológicos con detección fácil de formas tripomastigotas al fresco, mediante frotis de sangre y con serología convencional positiva: hemaglutinación indirecta (HAI), fijación del complemento (FC) (Machado Guerreiro), inmunofluorescencia indirecta (IF), reacción inmunoenzimática (ELISA), de inmunoprecipitación: doble difusión (DD), inmunoelectroforesis (IEF), electrosineresis (ES), e inmunobloting (IB) con IgM postiva. Estos casos se tratan con NF $8 \mathrm{mg} /$ $\mathrm{kg} /$ día durante 30-60 días en adultos y $10 \mathrm{mg} / \mathrm{kg} /$ día por 30-60 días en niños. La dosis diaria se debe repartir en dos o tres tomas después de las comidas (cada 8 ó $12 \mathrm{~h}$ ). El ideal es comenzar con la mitad de la dosis, subir gradualmente diariamente hasta alcanzar al $4^{\circ}$ día los niveles óptimos. Esto permite

\section{Tabla 2. Reacciones adversas al nifurtimox y benznidazol}

\footnotetext{
Alteraciones generales y digestivas

Baja de peso

Malestar gástrico

Náuseas

Vómitos

Alteraciones hematológicas (por hipersensibilidad)

Leucopenia

Trombocitopenia

Agranulocitosis

Alteraciones dermatológicas

Eritema, rash sensible a la luz

Dermatitis atópica (leve o severa)

Ocasionalmente síndrome de Stevens Johnson que requiere la suspensión de la terapia

Alteraciones neurológicas

Polineuropatias dosis dependiente

En general se presenta en esquemas con altas dosis

Con las dosis habituales de $5 \mathrm{mg} / \mathrm{kg} / \mathrm{día}$ de BNZ, 10-30\% de los pacientes presentan algún tipo de compromiso neurológico
} 
mejorar la tolerancia al medicamento. La curación clínica, parasitológica y serológica de los casos agudos adquiridos es de $70 \%$ con $\mathrm{NF}^{36}$ y de $76 \%$ con BNZ. En Brasil nunca se utilizó NF, siempre se administró BNZ a dosis de $5 \mathrm{mg} / \mathrm{kg} /$ día por 60 días en adultos y $5-10 \mathrm{mg} / \mathrm{kg} /$ día en niños por 60 días $^{37}$.

\section{ii. congénitos}

El tratamiento se debe efectuar en el mismo momento en que se realiza el diagnóstico, es decir, cuando se confirma la sospecha clínica con las observaciones del parásito al fresco, en frotis de sangre, mediante microhematocrito o microstrout. Muchas veces el diagnóstico se confirma después de los 9 meses de vida del niño, por persistencia de serología positiva, es decir, cuando los anticuerpos positivos maternos han desaparecido. Los mejores resultados se obtienen mientras más precoz sea el diagnóstico. Si la terapia se realiza dentro del año de vida, la curación es del 100\% (clínica, parasitológica y serológica). Es importante realizar un seguimiento clínico, parasitológico y serológico de los recién nacidos ( $\mathrm{RN}$ ) tratados, por lo menos hasta los dos años. En los últimos años se ha confirmado la utilidad de la reacción de PCR de T. cruzi en el diagnóstico precoz. Su sensibilidad es mayor que la del xenodiagnóstico ${ }^{38-39}$. Hoy en día se acepta que PCR positivo en un RN no representa necesariamente una infección congénita, ya que restos del $\mathrm{ADN}$ del parásito (al ser destruido) pueden pasar la barrera placentaria (amplicones y no parásitos vivos). Por este motivo, es necesario repetir esta reacción a los 15 y/o 30 días Si persiste la positividad, recién entonces se confirmará la infección congénita. Los $\mathrm{RN}$ o lactantes deben recibir $\mathrm{NF}$ a dosis de $8-10 \mathrm{mg} / \mathrm{kg} /$ día por 60 días en tres dosis diarias (cada 8 h) o BNZ, 5-10 mg/kg/día por 60 días en tres dosis. Para evitar las convulsiones se asocia fenobarbital en dosis habituales durante los primeros 15 días.

\section{iii. Enfermedad de Chagas accidental}

Todos los accidentes de laboratorio en que hubo inoculo en forma virulenta de T. cruzi y confirmación de la infección humana mediante, serología convencional (después de los 21 días), PCR positiva o ambas para T. cruzi, deben recibir la misma terapia que los casos agudos adquiridos (vía vectorial u otra) durante 15 días. Se incluye en este grupo a la transfusión por error al administrar sangre o sus derivados de un donante chagásico.
Siempre es necesario realizar seguimiento de estos casos a los 30 y 60 días (clínico y serológico).

\section{Trasplante de órganos}

Un trasplante con un dador o receptor con ECh debe ser siempre tratado con NF $8 \mathrm{mg} / \mathrm{kg} /$ día en adultos y $10 \mathrm{mg} / \mathrm{kg} /$ día en niños por 60 días o BNZ $5 \mathrm{mg} / \mathrm{kg} /$ día en adultos y $5-10 \mathrm{mg} /$ $\mathrm{kg} /$ día en niños (promedio 7,5 mg) por 60 días. En trasplantes de médula ósea la terapia se debe mantener por 2 años. En los trasplantados pueden ocurrir primoinfecciones y reactivaciones, por este motivo, es importante efectuar exámenes previos al trasplante, al dador y al receptor. En los casos que se trasplante un órgano de cadáver es posible detectar anticuerpos anti T.cruzi en el líquido pericárdico. Las primoinfecciones se tratan de igual forma que los casos adquiridos agudos, las reactivaciones de un paciente con ECh crónica se describen a continuación.

\section{Reactivación de la enfermedad de Chagas crónica y tratamiento de la enfermedad de Chagas en inmunosuprimidos}

Los pacientes con ECh crónica que presentan una coinfección con el virus de la inmunodeficiencia humana, o que sean sometidos a una terapia de inmunosupresión por cáncer, leucemias, etc, deben recibir el mismo esquema terapéutico que los casos agudos adquiridos por 5 o más meses. En la primoinfección por T. cruzi en pacientes con SIDA se administra el mismo esquema terapéutico que en las reactivaciones hasta que se reconstituya la respuesta inmunológica del hospedero, por lo general a los 60 días o más. Una vez que se normaliza el sistema inmune, especialmente la relación linfocitos CD8 (igual o superior a 200 por $\mathrm{ml}$ ), el tratamiento antiparasitario se administra cada 3 días, balanceando siempre la acción parasiticida con los efectos adversos de los fármacos. Los pacientes con SIDA sin terapia anti-retroviral son los más afectados por la primoinfección por T. cruzi. En ellos una vez que el nivel de linfocitos CD4 se normaliza con la terapia anti-retroviral se debe administrar el esquema de mantención anti T. cruzi.

\section{Evaluación y seguimiento del tratamiento}

Las dificultades de la terapia etiológica de la ECh radica en: la prolongada duración de ésta que por lo general es de 30 a 60 días, por los efectos colaterales de los fármacos, que se presentan en 
$30 \%$ de los casos y la falta de un criterio fidedigno de curación en los casos crónicos ${ }^{40-41}$. Para algunos investigadores, la conversión serológica es indicación de curación, pero esto sólo sucede en $70-75 \%$ de los casos adquiridos agudos y en $100 \%$ de los casos agudos congénitos, y en los casos crónicos muchas veces 20 a 30 años después del término de la terapia y en muchos casos los pacientes fallecen antes que esto suceda. Es decir, en los casos crónicos puede haber curación parasitológica con serología convencional positiva. En recientes estudios en animales infectados con T. cruzi y curados que no presentaban parásitos ni antígenos de T. cruzi tenían linfocitos $\mathrm{CD}_{8}$ centrales de memoria que mantenían una serología positiva por más de un año ${ }^{42}$. No sabemos si esto sucede en el humano, pero si así fuera explicaría la cura parasitológica en casos crónicos sin conversión serológica. En base a nuestra experiencia en el tratamiento de esta zoonosis consideramos como criterio de cura en el período crónico, la conversión del xenodiagnóstico y del PCR cualitativo de positivo a negativo y, en los cardiópatas, la eliminación de las alteraciones electrocardiográficas, cambios que deben persistir por 12 o más años, independientemente de la conversión serológica. Debe existir dos parámetros parasitológicos y uno o más clínicos para confirmar la curación ${ }^{11}$. La desaparición de los anticuerpos líticos como un complemento de los criterios de curación, se considera válido por algunos investigadores. A todos los pacientes chagásicos tratados tanto en el período agudo, período crónico determinado inicial o intermedio y en el período crónico indeterminado se les debe efectuar un seguimiento con evaluaciones clínicas, parasitológicas (cualitativas y cuantitativas) y serológicas por períodos prolongados ${ }^{43-45}$. Es necesario considerar que en pacientes inmunosuprimidos y con ECh la serología convencional es habitualmente negativa y por consiguiente no es útil para el seguimiento de estos casos.

\section{Resistencia del T. cruzi a fármacos}

Se ha demostrado que existen cepas de T. cruzi resistentes a NF o BNZ. Nosotros hemos observado que pacientes con ECh crónica tratados con ITRA y que no responden al tratamiento, es decir, no presentaron curación parasitológica estaban infectados con el linaje T. cruzi I, mientras los que respondían a la terapia tenían linaje T. cruzi II, su- giriendo que el linaje TcI es resistente a ITRA ${ }^{46,47}$.

\section{Contraindicaciones del tratamiento}

La utilización de NF y BNZ en pacientes chagásicos está contraindicado en embarazadas, mujeres en período de lactancia, pacientes con alcoholismo crónico invertebrado y en personas con hepatopatías, nefrópatas y hemopatías graves.

\section{Comentarios finales}

En la actualidad no existe un tratamiento etiológico eficaz sin efectos colaterales y de fácil adquisición. En las formas agudas, con NF y BNZ se obtiene 70 a $75 \%$ de curación que aumenta al $100 \%$ en los casos congénitos. En el período crónico, la cifra de curación apenas alcanza 30\% Nosotros, con ITRA, obtuvimos $20 \%$ de cura parasitológica (sin conversión serológica) y $50 \%$ de mejoría electrocardiográfica de los cardiópatas en estado inicial. Se necesitan nuevos fármacos más eficaces, sin efectos secundarios y de bajo costo. Lamentablemente la industria farmacéutica internacional ha demostrado escaso interés en esta parasitosis que pertenece a las enfermedades olvidadas o dejadas de lado ("neglected diseases") y que afectan a una población de escasos recursos ${ }^{48}$. Es posible que el POSA, relacionado con ITRA, pueda en un futuro cercano ser utilizado en la ECh humana. Laboratorio Bayer ha fabricado una nueva partida de NF a base de micropartículas, lo que facilita su administración y disminuye los efectos secundarios. El Ministerio de Salud de Chile adquirió parte de este nuevo NF. Hasta la fecha lo hemos aplicado en aproximadamente 100 personas jóvenes con ECh crónica y nos ha llamado la atención la buena tolerancia al fármaco en relación a experiencias anteriores.

Entre 60 y $80 \%$ de los chagásicos cursan el período crónico indeterminado, es decir, no presentan signos ni síntomas y los exámenes de laboratorio rutinarios son normales: radiografías de tórax, electrocardiograma, radiografía de esófago, estómago y duodeno, hemograma-VHS y perfil bioquímico. Cincuenta a $55 \%$ de estos pacientes permanecerán en esta etapa toda su vida, otros después de un tiempo variable presentarán alteraciones cardiacas (30-40\%), digestivas, o ambas.

El problema radica que en la actualidad no existe un indicador que permita señalar cuál(es) 
de los pacientes que cursan este período crónico indeterminado va a desarrollar una forma determinada y quiénes permanecerán en este período. Por este motivo, nosotros tratamos a los pacientes en esta etapa para evitar que desarrollen una cardiopatía, que es evolutiva y por lo general de mal pronóstico. En una investigación que efectuamos, se demostró que los pacientes en período crónico indeterminado tratados con ITRA desarrollan menos cardiopatías que los pacientes no tratados ${ }^{11}$, resultados similares fueron observados en Argentina utilizando $\mathrm{BNZ}^{41}$. Desde el año 2006 a la fecha se está desarrollando un estudio multicéntrico a doble ciego (Proyecto BENEFIT) de cardiópatas chagásicos tratados con BNZ o placebo. Los resultados definitivos estarán disponibles en los años 2011-2012. El primer trabajo piloto realizado con 300 personas tuvo como objetivo conocer la tolerancia y adherencia de los pacientes a la terapia ( 150 con el fármaco y 150 con placebo). La investigación principal consiste en tratar 6.000 pacientes divididos en dos grupos que reciben $\mathrm{BNZ}$ o placebo. En el primero de ellos, se tratará a 1.500 cardiópatas chagásicos con 5 $\mathrm{mg} / \mathrm{kg}$ /día de BNZ (con un máximo de $400 \mathrm{mg}$ al día) por 60 días y 1.500 cardiópatas con placebo. El segundo grupo de 1.500 se tratarán con $5 \mathrm{mg} /$ kg por día (con un máximo de $300 \mathrm{mg}$ ) al día por 60 días, con una dosis variable dependiendo del peso de la persona ejemplo: un cardiópata de 60 kilos recibirá la terapia por 60 días el de 40 kilos por 40 días y el de 80 kilos por 80 días. 1.500 cardiópatas chagásicos constituirán el grupo control que recibirá placebo ${ }^{48}$.

Agradecimientos: Los autores agradecen al Dr. Juan Diego Maya por permitir la publicación de las Figuras originales 1 y 2

\section{Referencias}

1. Aufderheide AC, Salo W, Madden M, Streitz J, Buikstra J, Guhl F, et al. 9000-year record of Chagas' disease. Proc Natl Acad Sci USA 2004; 101: 2034-9.

2. Apt W. [Treatment of Chagas disease]. Rev Med Chile 1985; 113: 162-6.

3. Pinto Dias J. Tratamiento etiológico de la enfermedad de Chagas. En XII Reunión de la Comisión Intergubernamental del Cono Sur para la eliminación de Triatoma infestans y la interrupción de la transmisión transfusio- nal de la Tripanosomiasis Americana (INCOST/Chagas) 2004. pp 129-34. Washington DC. Pan American Health Organization.

4. Coura R. Chagas disease: clinical and therapeutic features. Enf Emerg 2005; 8: 18-24.

5. Steverding D, Tyler K. Novel antitrypanosomal agents. Expert Opin Investig Drugs 2005; 14: 939-55.

6. Andrade Z, Andrade S. Patología Da Doença de Chagas. En: Brener Z, Andrade Z, Barral-Neto M. (eds). Trypanosoma cruzi e doença de Chagas 2da. Edición. Río de Janeiro Guanabara Koogan 2000; 201-30.

7. Teixeira A, Nascimento R, Sturn N. Evolution and pathology in Chagas disease. A Review. Mem Inst Oswaldo Cruz 2006; 101: 463-91.

8. Brener Z. Terapéutica experimental na doença de Chagas. Trypanosoma cruzi e Doença de Chagas. Eds. Brener Z, Andrade Z. y Barral-Neto M, Guanabara Koogan. Rio de Janeiro 2000; 379-88.

9. Avila J, Avila A. Trypanosoma cruzi allopurinol in the treatment of mice with experimental acute Chagas disease. Exp Parasitol 1981; 51: 204-8.

10. Avila J, Avila A, Muñoz E, Monzon H. Trypanosoma cruzi: 4-aminopyrazolopyrimidine in the treatment of experimental Chagas disease. Exp Parasitol 1983; 56: 236-40.

11. Apt W, Arribada A, Zulantay I, Solari A, Sánchez G, Mundaca $\mathrm{K}$, et al. Itraconazole and Allopurinol in the treatment of chronic American tripanosomiasis: the results of clinical and parasitological examinations 11 years post treatment. Ann Trop Med Parasitol 2005; 99: 733-41.

12. Tomimori-Yamashita J, Deps P, Almeida D, Enokihara M, De Seixas M, Freymuller E. Cutaneous manifestation of Chagas disease after heart transplantation: successful treatment with allopurinol. Br J Dermatol 1997; 137: 626-30.

13. Apt W, Aguilera X, Arribada A, Pérez C, Miranda C, Sánchez G, et al. Treatment of chronic Chagas disease with itraconazole and allopurinol. Am J Trop Med and Hyg 1998; 59: 133-8.

14. Urbina J. Chemotherapy of Chagas disease. Curr Pharm Des 2002; 8:287-95.

15. Zulantay I, Apt W, Gil L.C, Rocha C, Mundaca C, Solari A, et al. The PCR-based detection of Trypanosoma cruzi in the faeces of Triatoma infestans fed on patients with chronic American trypanosomiasis gives higher sensitivity and a quicker result than routine xenodiagnosis. Ann Trop Med Parasitol 2007; 101: 673-9.

16. Skies D, Vázquez J, Anstead G, Greybill J, Reynes J, Ward D, et al. Posaconazole for the treatment of azolerefractory oropharyngeal and esophaged candidiasis in 
subjects with HIV infection. Clin Infect Dis 2007; 44: 607-14.

17. Urbina J. New chemotherapeutic approaches for the treatment of Chagas disease (American Trypanosomiasis). Expert Opin Ther Patents 2003; 13: 661-9.

18. Maya J, Cassels B, Iturriaga-Vásquez P, Ferreira J, Faún$\operatorname{dez} \mathrm{M}$, Galanti N, et al. Mode of action of natural and synthetic drugs against Trypanosoma cruzi and their interaction with the mammalian host. Comp Biochem Physil 2006; 1-20.

19. Cazzulo J. Proteinases of Trypanosoma cruzi: patential targets for the chemotherapy of Chagas desease. Curr Top Med Chem 2002; 2: 1261-71.

20. Garzoni L, Waghabi M, Baptista M, de Castro S, Meirelles M, Britto C, et al. Antiparasitic activity of risedronate in a murine model of acute Chagas disease. Int J Antimicrob Agents 2004; 23: 286-90.

21. Hucke O, Gelb M, Verlinde C, Buckner F. The protein farnesyltransferase inhibitor Tipifarnib as a new lead for the development of drugs against Chagas disease. J Med Chem 2005; 48: 5415-8.

22. Lepesheva G, Zaitseva N, Nes W, Shou W, Arase M, Liu J, et al. CYP51 from Trypanosoma cruzi: a phyla-specific residue in the B'helix define substrate preferences of sterol 14 alpha-demethylase. J Biol Chem 2006; 281: 3577-85.

23. Niemirowicz G, Parussini F, Aguero F, Cazzulo J. Two metallocarboxypeptidases from the protozoan Trypanosoma cruzi belong to the M32 family, found so far only in prokaryotes. Biochem J 2007; 401: 399-410.

24. Rawlings N. Unusual phyletic distribution of peptidases as a tool for identifying potential drug targets. Biochem J 2007; 401: 5-7.

25. Morello A, Lipchenca I, Cassels B, Speisky H, Aldunate J, Repetto Y. Trypanocidad effect of boldine and related alkaloids up on several strains of Trypanosoma cruzi. Comp Biochem Physiol 1994; 90: 1-12.

26. Tempone A, Borborema S, de Andrade H Jr, de Amorim N, Yogi A, Carvalho C, et al. Antiprotozoal activity of Brazilian plant extracts from isoquinoline alkaloidproducing families. Phytomedicine 2005; 12: 382-90.

27. Rubio J, Calderón J, Flores A, Castro C, Céspedes C. Trypanocidad activity of oleoresin and terpenoids isolated from Pinus oocarpa. Naturforsch 2005; 60: 711-6.

28. Uchiyama N, Kabututu Z, Kubata B, Kiuchi F, Ito M, Nakajima-Shimada J, et al. Antichagasic activity of komaroviquinone is due to generation of reactive oxygen species catalyzed by Trypanosoma cruzi old yellow enzyme. Antimicrob Agents Chemother 2005; 49: 5123-6.

29. Leite J, Oliveira A, Lombardi J, Filho J, Chiari E. Trypanocidal activity of triterpenes from Arrabidaea tripli- nervia and derivatives. Biol Pharm Bull 2006; 29: 2307-9.

30. De Oliveira C, Santana L, Carmona A, Cezari M, Sampaio M, Sampaio C, et al. Structure of cruzipain/cruzain inhibitors isolated from Bauhinia bauhinioides seeds. Biol Chem 2001; 382: 847-52.

31. Rassi A, Rassi Jr A, Rassi S. Cardiopatía crónica: arritmias. En Pinto Dias J. Coura J (eds). Doença de Chagas. Um manual para o clinico general. Río de Janeiro. Fio Cruz 1997; 201-22.

32. Prata A. Abordagem general do paciente chagasico. En Pinto Dias J. Coura (eds). Clinica e terapeutica do doença de Chagas. Um manual para o clinico general. Rio de Janeiro. Fio Cruz 1997; 115-26.

33. Pinto Dias J. The treatment of Chagas Disease (South American tripanosomiasis) Ann Int Med 2006; 144: 772-4.

34. Viotti R, Vigliano C, Lococo B, Álvarez M, Petti M, Bertochi $\mathrm{G}$, et al. Side effects of benznidazole as treatment of Chagas disease: fears and realities. Expert Rev Anti Infect Ther 2009; 7: 157-63.

35. Apt W, Heitman I, Jercic MI, Jofré L, Muñoz P, et al. Guías clínicas de la enfermedad de Chagas. Parte VI. Tratamineto antiparasitario para enfermedad de Chagas. Rev Chil Infectol 2008; 25: 384-9.

36. Cerisola J. Evolución serológica de pacientes con enfermedad de Chagas aguda tratados con Bay 2502. Bol Chile Parasitol 1969; 24: 54-9.

37. Cançado R. Tratamiento etiológico do doença de Chagas pelo benznidazol. Capítulo 19. Libro Trypanosoma cruzi e doença de Chagas Eds. Brener Z, Andrade Z. y BarralNeto M. Guanabara Koogan, Río de Janeiro 2000; 389405.

38. Virreira M, Torrico F, Truyens C, Alonso-Vega C, Solano M, Carlier Y, et al. Comparison of polymerase chain reaction methods for reliable and easy detection of congenital Trypanosoma cruzi infection. Am J Trop Med Hyg 2003; 68: 574-82.

39. Sánchez O, Mora M., Basombrio M. High prevalence of congenital Trypanosoma cruzi infection and clustering in Salta, Argentina. Pediatrics 2005; 115: 668-72.

40. WHO. Control of Chagas disease. WHO Technical Report Series 2000; 905 Geneva.

41. Viotti R, Vigliano C, Lococo B, Bertocci G, Petti M, Álvarez M, et al. Long-term cardiac outcome of treating chronic Chagas disease with benznidazole versus no treatment: a nonrandomized trial. Ann Intern Med 2006; 144: 724-34.

42. Bustamante J, Bixby L, Tarleton R. Drug induced cure drives conversion to a stable and protective CD8+ T central memory response in chronic Chagas disease. Nat Med 2008; 14: 542-50. 
43. Duffy T, Bisio M, Altcheh J, Burgos I, Díaz M, Levin M, et al. Accurate real-time PCR strategy for monitoring bloodstream parasites loads in Chagas disease patients. PLoS Negl Trop Dis 2009; 3: 419-29.

44. Britto C. Usefulness of PCR-based assays to assess drug efficacy in Chagas disease chemotherapy: value and limitations. Mem Inst Oswaldo Cruz 2009; 104: 122-35.

45. Marin-Neto JA, Rassi A Jr, Morillo CA, Avezum A, Connolly SJ, Sosa-Estani S, et al. BENEFIT Investigators. Rationale and design of a randomized placebo-controlled trial assessing the effects of etiologic treatment in Chagas' cardiomyopathy: the benznidazole evaluation for interrupting trypanosomiasis (BENEFIT) Am Heart J
2008; 156: 37-43.

46. Filardi L, Brener Z. Susceptibility and natural resistance of Trypanosoma cruzi strains to drugs used clinically in Chagas disease. Trans Roy Soc Trop Med Hyg 1987; 81:755-9.

47. Coronado X, Zulantay I, Rozas M, Apt W, Sánchez G, Rodríguez J, et al. Dissimilar distribution of Trypanosoma cruzi clones in humans alter chemotherapy with allopurinol and itraconazole. J Antimicrob Chemother 2006; 58: 216-9.

48. Rassi A Jr, Dias JC, Marín-Neto J, Rassi A. Challenges and opportunities for primary, secondary, and tertiary prevention of Chagas' disease. Heart 2009; 95: 524-34. 